\title{
BMJ Global Health Early initiation of breast feeding on the rise in India
}

\author{
Víctor M Aguayo, ${ }^{1}$ Gagan Gupta, ${ }^{2}$ Gayatri Singh, ${ }^{2}$ Rakesh Kumar $^{3}$
}

To cite: Aguayo VM, Gupta G, Singh G, et al. Early initiation of breast feeding on the rise in India. $B M J$ Global Health 2016;1: e000043. doi:10.1136/ bmjgh-2016-000043

Received 18 February 2016 Revised 5 July 2016 Accepted 6 July 2016

CrossMark

\footnotetext{
${ }^{1}$ United Nations Children's Fund (UNICEF) Regional Office for South Asia, Kathmandu, Nepal ${ }^{2}$ UNICEF Country Office, New Delhi, India ${ }^{3}$ Ministry of Health and Family Welfare, New Delhi, India
}

Correspondence to Dr Víctor M Aguayo; vaguayo@unicef.org
In India, 1.2 million children aged 0-59 months die yearly. An estimated $58 \%$ of these deaths occur during the neonatal period (ie, the first 28 days of life). ${ }^{1}$ A meta-analysis of three large trials conducted in Ghana, India and Nepal found that early initiation of breast feeding was associated with a $44 \%$ lower risk of neonatal mortality (RR 0.56 ; $95 \%$ CI 0.40 to 0.79$).^{2-5}$ More recently, analyses on a large cohort of almost 100000 newborns from three large trials in Ghana, India and Tanzania has shown that, compared with infants who initiated breast feeding within the first hour of life, the risk of neonatal death among children who initiated breast feeding between 2 and 23 hours after birth was $41 \%$ higher (RR $1.41 ; 95 \%$ CI 1.24 to 1.62 ), and $79 \%$ higher among those who initiated breast feeding at 24-96 hours of birth (RR 1.79; 95\% CI 1.39 to 2.30$).{ }^{6}$ Therefore, supporting mothers to initiate breast feeding within 1 hour of delivery is a proven high-impact intervention for neonatal survival. ${ }^{78}$

In 2006, India's National Family Health Survey indicated that only $24.5 \%$ of newborns were breast fed within 1 hour of birth as recommended by India's Ministry of Health and the WHO. Furthermore, in Bihar, Chhattisgarh, Jharkhand, Madhya Pradesh, Odisha, Rajasthan and Uttar Pradesh-the seven states where $55 \%$ of Indian infants were born and $64 \%$ of newborn deaths occurred-the combined rate of early initiation of breast feeding was a mere $12.5 \%$. $^{9}$

Since 2006, the Government of India and India's state governments-with technical support from UNICEF and other partnershave been implementing a comprehensive eight-pronged strategy to support breast feeding: (1) incorporating outputs and budgets to support breast feeding in the annual implementation plans of India's flagship programmes for child health, nutrition and development, namely the National Health Mission and the Integrated Child

\section{Summary Box}

- In India, a multipronged strategy including large scale programmes, effective capacity building initiatives, strong partnerships, communitybased action, and strategic mass media communication led to an increase in the rates of early initiation of breastfeeding from $24.5 \%$ in 2006 to $44.6 \%$ in 2014 (i.e. a 1.8-fold increase).

- In the seven states of India with the highest burden of neonatal mortality, the combined rate of early initiation of breastfeeding increased from $12.5 \%$ in 2006 to $34.4 \%$ in 2014 (i.e. a 2.7-fold increase).

- But there is room for further improvement - in $2014,81.1 \%$ of deliveries were attended by a skilled health provider, while only $44.6 \%$ of newborns were breast fed within 1 hour of birth, indicating that rates of early initiation of breast feeding could double if all newborns delivered by a health provider were breast fed within 1 hour of birth.

- There is an urgent need to continue to strengthen national and state policies, hospital and maternity practices, and the knowledge and skills of birth attendants-physicians, midwives and nurses-to support early initiation of breast feeding as a key component of essential newborn care.

Development Services, the largest of their kind in the world; ${ }^{10}{ }^{11}$ (2) mainstreaming support for early initiation of breast feeding in the scale-up of Janani Suraksha Yojana, the national conditional cash transfer programme to increase births in health facilities and reduce maternal and neonatal deaths; ${ }^{12}$ (3) ensuring support for breast feeding in special newborn care units, which provide care for sick newborns with birth asphyxia, jaundice, sepsis or low birth weight; ${ }^{13}$ (4) forging alliances with training colleges, medical schools and professional bodies such as the Indian Academy of Paediatrics to mainstream breast feeding into the preservice curricula of health professionals; ${ }^{14}$ (5) building the capacity of practising physicians, midwives and nurses to ensure that 
women who deliver in a health facility are supported to breast feed within 1 hour of birth: ${ }^{15}$ (6) strengthening the capacity of community frontline workers of the National Health Mission and the Integrated Child Development Services programmes to provide mothers -during and after pregnancy - with counselling on and support for optimal breast feeding; ${ }^{16-18}$ (7) mainstreaming support for breast feeding in the work of grassroots women's groups and non-governmental organisations to promote positive behaviour and social change for breast feeding; and (8) communicating the benefits of breast feeding through large-scale media campaigns. ${ }^{19} 20$

These efforts seem to be paying off. In 2009, India's National Coverage Evaluation Survey indicated that the rate of initiation of breast feeding within 1 hour of birth had increased from $24.5 \%$ to $34 \%$ nationally. ${ }^{21}$ In 2011 , a survey in the country's 100 poorest districts-home to over $20 \%$ of India's children-indicated that early initiation of breast feeding had increased from $20 \%$ in 2007 to $37 \%$ in 2011. ${ }^{22}$ Finally, a national survey in 2014 indicated that early initiation of breast feeding had increased from $24.5 \%$ in 2006 to $44.6 \%$ in 2014 (ie, a 1.8-fold increase) with an average annual rate of increase of $10.3 \%$. Importantly, in the seven states with the highest burden of neonatal mortality, the combined rate of early initiation of breast feeding increased from $12.5 \%$ in 2006 to $34.4 \%$ in 2014 (ie, a 2.7-fold) with an average annual rate of increase of $21.8 \% .^{23}$ This evidence seems to indicate that focused strategies, effective capacity-building initiatives, strong partnerships, vibrant community-based action, and strategic mass media communication contributed to double/triple the rate of early initiation of breast feeding.

However, these data also indicate that room for further improvement still exists. The 2014 national survey shows that $81.1 \%$ of deliveries were attended by a skilled health provider, while only $44.6 \%$ of newborns were breast fed within 1 hour of birth (figure 1), indicating that rates of early initiation of breast feeding could almost double if all newborns delivered by a health provider were breast fed within 1 hour of birth. Recent meta-analyses of health system- and community-based studies worldwide indicate that improving individual counselling or group education, supporting immediate breast feeding at delivery, and training health staff in lactation management (three interventions included in the Baby Friendly Hospital Initiative) increased the likelihood of early initiation of breast feeding by at least $20 \%$. In addition, community-based group counselling and home-based individual counselling focusing on infant feeding decision-making and preparation for breast feeding increased the likelihood of early initiation of breast feeding by $65 \%$ and $74 \%$, respectively. ${ }^{24} 25$

Breast feeding initiation can be particularly delayed for infants born by caesarean section. India's National Family Health Survey 2015 shows that, in states such as Andhra Pradesh and Telangana, where 92\% of deliveries are attended by skilled health providers, high prevalences of births by caesarean section (40\% in Andhra Pradesh and $58 \%$ in Telangana) are associated with low rates of early initiation of breast feeding $(37 \%$ in Telangana and $40 \%$ in Andhra Pradesh). Furthermore, prospective cohort studies in India have shown that infants born by caesarean section were almost four times less likely to initiate breast feeding within 1 hour of birth than infants born by vaginal delivery. ${ }^{26}$ However, global evidence suggests that, in the presence of adequate support, a caesarean section is not necessarily a barrier to timely initiation of breast feeding. ${ }^{24}$

Therefore, there is an urgent need to continue to strengthen national and state policies, hospital and maternity practices, and the knowledge and skills of birth attendants-physicians, midwives and nurses-to support early initiation of breast feeding as a key component of essential newborn care. Janani Suraksha Yojna and Indira Gandhi Matriva Sahyog Yohana-India's conditional cash transfer programmes to protect women during pregnancy, delivery and lactation-need to step up their efforts to ensure that facility- and community-

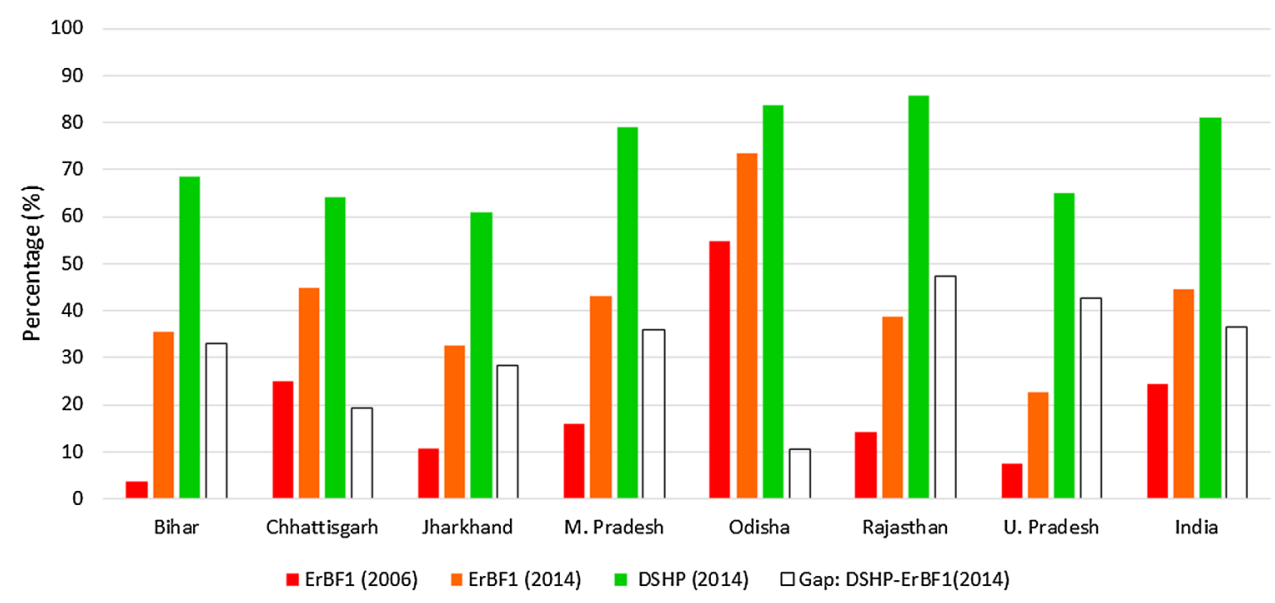

Sources: NFHS-2006, RSOC-2014

Figure 1 Early initiation of breast feeding within 1 hour of delivery (ErBF1), deliveries attended by a skilled health provider (DSHP), and gap between DSHP and ErBF1 in the seven states in India with the highest burden of neonatal mortality. 
based health workers provide mothers and families with timely information and counselling to support early initiation of breast feeding. The guidelines of Janani Suraksha Yojna include the promotion of early initiation of breast feeding as one of the responsibilities of the accredited social health activist, the incentivised community-based worker under Janani Suraksha Yojna. Similarly, supporting early and exclusive breast feeding is one of the objectives of the Indira Gandhi Matriva Sahyog Yohana programme. Private providers, who deliver up to $50 \%$ of the newborns in states such as Andhra Pradesh and Gujarat, also have a major role to play in ensuring that their newborn care practices are aligned with national policy and guidance to support early initiation of breast feeding. Both public and private sector providers need to reach out to mothers, families and communities with one unequivocal message: early initiation of breast feeding saves lives.

\section{Handling editor Seye Abimbola}

Contributors VMA led data analysis and manuscript writing. GG, GS and RK contributed to data interpretation and manuscript writing.

Disclaimer The opinions expressed in this paper are those of the authors and do not necessarily represent an official position of the organisations with which they are affiliated.

Funding UNICEF Regional Office for South Asia for analysis and manuscript writing.

\section{Competing interests None declared.}

Provenance and peer review Not commissioned; externally peer reviewed.

Data sharing statement No additional data are available.

Open Access This is an Open Access article distributed in accordance with the Creative Commons Attribution Non Commercial (CC BY-NC 4.0) license which permits others to distribute, remix, adapt, build upon this work noncommercially, and license their derivative works on different terms, provided the original work is properly cited and the use is non-commercial. See: http:// creativecommons.org/licenses/by-nc/4.0/

\section{REFERENCES}

1. United Nations Children's Fund (UNICEF), World Bank Group (WBG), World Health Organization (WHO), United Nations (UN) for the UN Inter-agency Group for Child Mortality Estimation (UN IGME). Levels and trends in child mortality. New York: UNICEF, 2015.

2. Edmond KM, Zandoh C, Quigley MA, et al. Delayed breastfeeding initiation increases risk of neonatal mortality. Pediatrics 2006;117: e380-6.

3. Mullany LC, Katz J, Li YM, et al. Breastfeeding patterns, time to initiation, and mortality risk among newborns in southern Nepal. J Nutr 2008;138:599-603.

4. Garcia CR, Mullany LC, Rahmathullah L, et al. Breastfeeding initiation time and neonatal mortality risk among newborns in South India. J Perinatol 2011;31:397-403.

5. Debes AK, Kohli A, Walker N, et al. Time to initiation of breastfeeding and neonatal mortality and morbidity. A systematic review. BMC Public Health 2013;13(Suppl 3):S19.

6. NEOVITA Study Group. Timing of initiation, patterns of breastfeeding, and infant survival: prospective analysis of pooled data from three randomized trials. Lancet Global Health 2016;4:e266-75.
7. Bhutta ZA, Das JD, Rizvi A, et al. Evidence-based interventions for improvement of maternal and child nutrition. What can be done and at what cost? Lancet 2013;382:452-77.

8. World Health Organization (WHO). Essential nutrition actions. Improving maternal, newborn, infant and young child health and nutrition. Geneva, Switzerland: WHO, 2013.

9. International Institute of Population Sciences (IIPS). National Family Health Survey 2005-06 (NFHS-3). National Report. Mumbai, India: IIPS, 2007.

10. Ministry of Health and Family Welfare (MHFW), Government of India. India newborn action plan. New Delhi, India: Ministry of Health and Family Welfare, 2014.

11. Ministry of Women and Child Development (MWCD), Government of India. Integrated Child Development Services (ICDS). The broad framework for implementation. New Delhi, India: Ministry of Women and Child Development, 2012.

12. Ministry of Health and Family Welfare (MHFW), Government of India. Janani Suraksha Yojana. Features and frequently asked questions. New Delhi, India: Ministry of Health and Family Welfare, 2006. http://nrhm.gov.in/images/pdf/programmes/jsy/guidelines/jsy_ guidelines_2006.pdf

13. Ministry of Health and Family Welfare, Government of India. Facility-based newborn care operational guide. Guidelines for planning and implementation. New Delhi, India: Ministry of Health and Family Welfare, 2011.

14. Indian Academy of Pediatrics (IAP), Infant and Young Child Feeding Chapter. Infant and young child feeding guidelines, 2010. Indian Pediatrics 2010;47:995-1004.

15. Ministry of Health and Family Welfare, Government of India. Guidelines for pregnancy care and management of common obstetric complications by medical officers. New Delhi, India: Ministry of Health and Family Welfare, 2005.

16. National Rural Health Mission (NRHM), Government of India. Skills that save lives. Training manual for Accredited Social Health Activists (ASHA). Module 6: Focus on Maternal and Newborn Health. New Delhi, India: Ministry of Health and Family Welfare, 2011.

17. Ministry of Health and Family Welfare, Government of India Guidelines for antenatal care and skilled attendance at birth by Auxiliary Nurse-Midwives (ANM) and Lady Health Visitors (LHV). New Delhi, India: Ministry of Health and Family Welfare, 2005.

18. Ministry of Women and Child Development (MWCD), Institute of Public Cooperation and Child Development (NIPCCD), Government of India. Handbook for anganwadi workers. New Delhi, India: NIPCCD and MWCD, 2006.

19. Kyunki...Jeena Issi Ka Naam Hai (because...that's what life is). Entertainment-education soap opera (2008-2011). http://www. healthphone.org/ammaji/early-initiation-and-colostrum-feeding.htm (accessed 24 Nov 2015).

20. Ministry of Women and Child Development (MWCD), Government of India, and United Nations Children's Fund (UNICEF). Kuposhan Bharat Chodho (Free India from Malnutrition) multi-media communication campaign with Aamir Khan, actor and film producer, as brand ambassador for Nutrition in India. http://www.youtube.com/ watch?v=clcWdwpT3tw (accessed 24 Nov 2015).

21. Ministry of Health and Family Welfare, Government of India, and United Nations Children's Fund (UNICEF). Coverage evaluation survey. All India Report. New Delhi, India: UNICEF, 2009.

22. Naandi Foundation. The HUNGaMA survey report. Fighting hunger and malnutrition. Hyderabad, India: Naandi Foundation, 2011.

23. Ministry of Women and Child Development (MWCD), Government of India. Rapid Survey on Children (RSOC) 2013-2014. Factsheets. MWCD, 2015. http://wcd.nic.in/ (accessed 25 Oct 2015).

24. Rollins NC, Bhandari N, Hajeebhoy N, et al. on behalf of The Lance Breastfeeding Series Group. Why invest, and what it will take to improve breastfeeding practices? Lancet 2016;387:491-504.

25. Sinha B, Chowdhury R, Sankar MJ, et al. Interventions to improve breastfeeding outcomes. A systematic review and meta-analysis. Acta Pædiatrica 2015;104:114-35.

26. Patel A, Bucher S, Pusdekar Y, et al. Rates and determinants of early initiation of breastfeeding and exclusive breast feeding at 42 days postnatal in six low and middle-income countries. A prospective cohort study. Reproductive Health 2015;12(S2):S10. 